\title{
Deniz Kabuğunun Beton Basınç Dayanımına Etkilerinin Araştırılması
}

\author{
Ferhat Aydin \\ Sakarya Uygulamalı Bilimler Üniversitesi, Teknoloji Fakültesi, İnşaat Mühendisliği Bölümü, Sakarya, Türkiye
}

\section{Özet}

Ülkemizin etkin deprem kuşağı etkisinde olması yapıların güvenirliği açısından büyük önem arz etmektedir. Büyük 1999 Marmara depremi sonrasında, özellikle kıyı kesimlerinde bulunan bölgelerde, mevcut yapı stokunun güvenirliği tartışııır hale gelmiştir. Geçmiş yıllarda denize yakın bölgelerde inşaa edilen yapılarda kullanılan betonun, karışımında deniz kabuğu ve deniz kumu kullanımının beton dayanımına etkisi toplumda büyük bir endişe oluşturmuştur. Bu nedenle betonda kullanılan agreganın içeresinde bulunan deniz kabuğu bileşenlerinin beton dayanımını nasıl etkilediğinin bilinmesi önemlidir.

Bu çalışmada deniz kumu ve deniz kabuğunun beton basınç dayanımına etkileri araştırılmıştır. Deniz kumunun hacimce \%3'ü ve \%6'sı oranlarında deniz kabuğu ikameli betonlar üretilmişsir. Düşük ve normal dayanımlarda üretilen betonların referans betonlara göre basınç dayanımlarındaki kayıp oranları belirlenmiştir. Yapılan testler sonucunda deniz kabuğu ile hazırlanan beton numunelerin referans betonlara göre normal dayanımlı betonlarda $\% 26$, düşük dayanımlı betonlarda ise $\% 45$ oranında basınç dayanımlarının azalabileceği tespit edilmiştir.

Anahtar Kelimeler: Deniz kabuğu, deniz kumu, beton, basınç dayanımı

\section{Investigation of Effects of Seashell on Concrete Compressive Strength}

\begin{abstract}
The fact that our country is under the influence of the earthquake zone is of great importance for the reliability of the buildings. After the 1999 Marmara earthquake, the reliability of the existing building stock became questionable, especially in the coastal areas. The effect of the use of seashells and sea sand in the concrete of coastal structures on concrete strength has been a major concern in society In the past years. Therefore, it is important to know how the seashell contained in the aggregate used in concrete affects the concrete strength.

In this study, the effects of sea sand and seashell on the compressive strength of concrete were investigated. Concretes with seashells were produced at a rate of $3 \%$ and $6 \%$ by volume of sea sand. The loss rates of the compressive strengths of the concrete produced at low and normal strengths compared to the reference concrete were determined. As a result of the tests, it was determined that compressive strength of sea shell concretes could be reduced by $26 \%$ in normal strength concrete and $45 \%$ in low strength concrete compared to reference concrete.
\end{abstract}

Key words: Seashell, sea sand, concrete, compressive strength

*Corresponding author: Address: Department of Civil Engineering, Faculty of Technology, Sakarya University of Applied Sciences, 54187, Sakarya TURKEY. E-mail address: ferhata@ subu.edu.tr, Phone: +902646160240 


\section{Giriş}

Ülkemizde ve dünyada yapıların taşıyıcı sistemlerde betonarme yapıların kullanımı diğer yapı malzemelerinden inşaa edilen yapılara karşılaştırıldığında büyük bir farkla tercih edilmektedir. Betonarme sistemin iki ana unsurundan biri olan betonun dayanımı yapıların güvenirliği açısından son derece önemli bir kriterdir. Taşıyıcı yapı elemanlarında kullanılan betonun basınç dayanımı yapının deprem yada diğer etkilere karşı yeterli dayanımı sağlaması açısından en başta gelen yeterliliklerdendir. Yapıların deprem gibi çeşitli etkenlerden dolayı yıkılması yada ağır hasar görmesinde beton basınç dayanımının büyük bir etkisi olduğu araştırmacılar tarafında kabul edilmektedir. 1999 Marmara depreminden sonra yapılan bir çalışmada [1] bölgede yıkılan veya ağır hasarlı çok sayıdaki yapının betonları karot alınarak incelenmiş ve bu yapıların \%80'nin beton kalitesinin C20 dayanım sınıfının altında olduğu belirlenmiştir. Betonun basınç dayanımı onu temsil eden en önemli karakteristik özeliği olmakla birlikte basınç dayanımının yeterli düzeyde olması için dikkat edilmesi gereken karışım dizaynından kürüne kadar bir çok etken bulunmaktadır. Betonun içerisinde karışım esnasında kil, silt ve organik maddelerin bulunması beton dayanımını düşürdüğü bilinmektedir.

Ülkemizde denize yakın bölgelerde ince agrega olarak deniz kumunun kullanılması ile birlikte deniz kumunun içeresinde bulunan çeşitli miktarlardaki deniz kabukları geçmiş yıllarda temizlenmeden kullanılmıştır. Çok sayıda eski yapıda kullanılan deniz kabuklu betonların dayanımlarında oluşan kayıplar kullanıcıları tedirgin etmektedir. İstanbul Kartal'ta 16 Şubat 2019 tarihinde extra bir kuvvet olmadan ansızın yıkılan ve 21 kişinin öldüğü, 17 kişinin yaralandığı binanın betonlarının incelenmesinde (Şekil 1) betonun içerisinde çok miktarda deniz kabuğunun olduğu belirlenmiştir. Bunun gibi bölgede bulunan çok sayıda yapının betonlarında deniz kabuğunun olduğu tahmin edilmektedir.

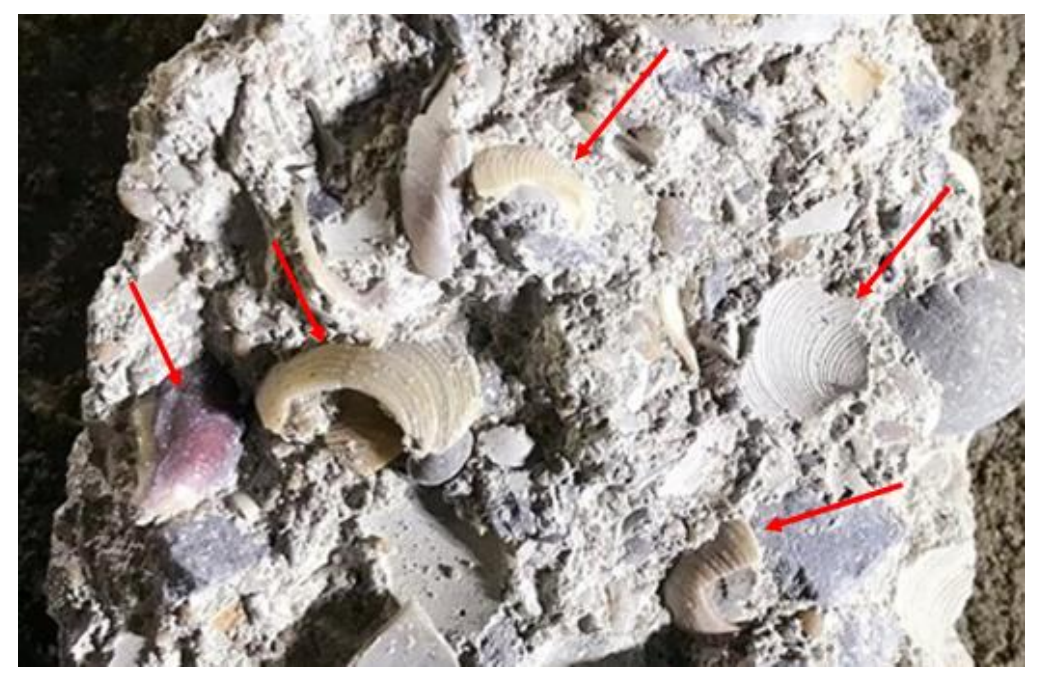

Şekil 1. İstanbul Kartal'da yıkılan binanın betonu [2]

Literatürde farklı özeliklere sahip deniz kabukları ile ilgili bir çok çalışma bulunmaktadır. Bu çalışmaların bir kısmı deniz kabuklarının öğütülerek çimentoda kullanımı [3-6] yada betonda ince 
agrega [7-10] veya iri agrega olarak kullanılması [11-14] ile ilgilidir. Deniz kabuklarının çimentoda kullanımı konusundaki çalışmalarda genellikle öğütülerek çimentonun genelde \%20'sini aşmayacak şekilde ikameler yapılarak basınç dayanımları incelenmiştir. Çimentoya ilave edilen deniz kabuklarının dayanımı büyük oranlarda düşürdüğü belirlenmiştir. Deniz kabuklarının betonda ince agrega yerine kullanımı konusundaki çalışmalar incelendiğinde çok farklı oranlarda ikame edilen çalışmaların bulunduğu genellikle çeşitli oranlarda basınç dayanımını düşürdüğü tespit edilmiştir. Betonda çeşitli deniz kabuklarının iri agrega yerine ikame edilerek kullanılan çalışmalarda yine benzer şekilde büyük oranlarda beton basınç dayanımının azaldığı görülmüştür. Dünyada yapılan çalışmalarda deniz kabuklarının betonda kullanılması ile ilgili basınç dayanımının yanında işlenebilirlik, taze ve kuru yoğunlukları, eğilme dayanımı, Elastisite modülü gibi özelikleri de incelenmiştir [15 ve 16].

Yapılan çalışmalara ek olarak bu çalışmada deniz kabuğu bulunan betonlarda ortaya çıkacak basınç dayanım dürüşlerinin oranlarını tahmin edebilmek amacıyla deniz kumu ile birlikte farklı dayanımlarda deniz kabuklu betonlar üretilerek basınç dayanımları tespit edilmiştir. Böylece betonda bulunabilecek deniz kabuğu miktarının dayanımı ne kadar etkilediği tahmin edilmiş olacaktır.

\section{Malzeme ve Metot}

Deniz kabuğunun betonda kullanımının beton dayanımının belirlenmesi amacıyla oluşturulan deney çeşitleri Tablo 1'de verilmiştir. Düşük ve normal dayanımlı olmak üzere iki farklı dayanım sinıfinda hazırlanan beton numunelerinde kullanılan deniz kumunun hacimce $\% 3$ ve $\% 6$ oranında deniz kabuğu ilave edilerek karışımlar yapılmıştır. Gerekli kür işlemleri uygulandıktan sonra her test grubundan üçer adet numune ile basınç testleri yapılan standart küp numunelerin basıç dayanımları hesaplanarak karşılaştırılmıştır.

Tablo 1. Deneylerde kullanılan beton türleri

\begin{tabular}{cc}
\hline Düşük Dayanımlı & Normal Dayanımlı \\
\hline Referans & Referans \\
\hline Deniz Kumlu & Deniz Kumlu \\
\hline \%3 Deniz Kabuklu & $\% 3$ Deniz Kabuklu \\
\hline$\% 6$ Deniz Kabuklu & $\% 6$ Deniz Kabuklu \\
\hline
\end{tabular}

Gerekli malzemelerin temininden sonra TS 802 [17] beton karışım ilkelerine uygun şekilde karışım oranları belirlenmiş̦tir. Tablo 2 ve Tablo 3 'te normal ve düşük dayanımlı betonların $1 \mathrm{~m}^{3}$ için ağırlıkça karışım oranları verilmiştir. Referans betonların dışındaki tüm karışımlarda ince agrega olarak deniz kumu kullanılmış, deniz kumlu numunelerde deniz kabuğu bulunmaktadır. 
Tablo 2. Normal dayanımlı beton karışım oranları $(\mathrm{kg})$

\begin{tabular}{ccccc}
\hline (kg) & $\begin{array}{c}\text { Referans } \\
\text { Beton }\end{array}$ & $\begin{array}{c}\text { Deniz } \\
\text { Kumlu }\end{array}$ & $\begin{array}{c}\text { \%3 } \\
\text { Deniz Kabuklu }\end{array}$ & $\begin{array}{c}\text { \%6 } \\
\text { Deniz Kabuklu }\end{array}$ \\
\hline Çimento & 386,8 & 386,8 & 386,8 & 386,8 \\
\hline Su & 205 & 205 & 205 & 205 \\
\hline Kum & 798,1 & 798,1 & 739,2 & 700,3 \\
\hline Deniz kabuğu & - & - & 20,7 & 41,5 \\
\hline Mıcır I & 354,8 & 354,8 & 354,8 & 354,8 \\
\hline Mıcır II & 621,0 & 621,0 & 621,0 & 621,0 \\
\hline Toplam & 2366 & 2366 & 2327,6 & 2309 \\
\hline
\end{tabular}

Tablo 3. Düşük dayanımlı beton karışım oranları $(\mathrm{kg})$

\begin{tabular}{ccccc}
\hline (kg) & $\begin{array}{c}\text { Referans } \\
\text { Beton }\end{array}$ & $\begin{array}{c}\text { Deniz } \\
\text { Kumlu }\end{array}$ & $\begin{array}{c}\text { \%3 } \\
\text { Deniz Kabuklu }\end{array}$ & $\begin{array}{c}\text { \%6 } \\
\text { Deniz Kabuklu }\end{array}$ \\
\hline Çimento & 273,3 & 273,3 & 273,3 & 273,3 \\
\hline Su & 205 & 205 & 205 & 205 \\
\hline Kum & 843,0 & 843,0 & 799,6 & 739,4 \\
\hline Deniz kabuğu & - & - & 21,9 & 43,8 \\
\hline Mıcır I & 374,6 & 374,6 & 374,6 & 374,6 \\
\hline Mıcır II & 655,6 & 655,6 & 655,6 & 655,6 \\
\hline Toplam & 2351 & 2351 & 2330 & 2330 \\
\hline
\end{tabular}

Deneylerde kullanılan deniz kumu ve deniz kabuğu Sakarya'nın Karasu ilçesi sahilinden temin edilmiştir (Şekil 2). Deniz kabuklarının özgül ağırlıkları yapılan testler sonucunda 2,43 gr/ $\mathrm{cm}^{3}$ bulunmuştur. Betona karıştırılmadan önce deniz kabukları kırılarak makul boyutlara getirilerek taze beton içerisine eklenmiştir. 

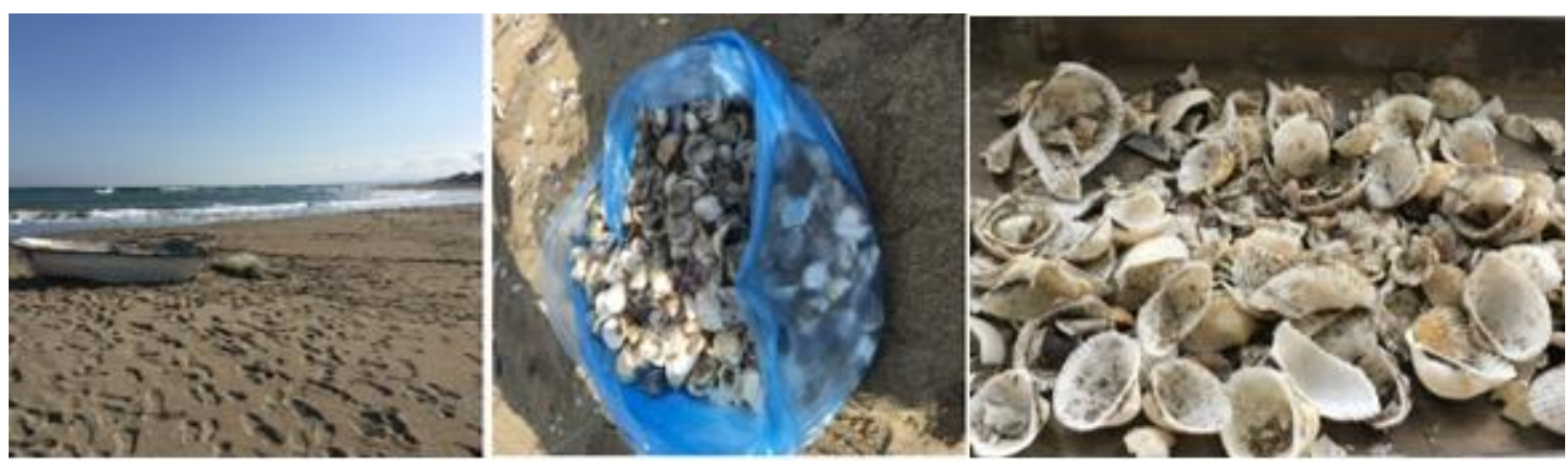

Şekil 2. Deneylerde kullanılan deniz kabukları

Karışım reçeteleri hazırlanarak belirlenen oranlarda bazı beton numunelere deniz kumunun hacimce \%3'ü ve \%6'sı oranında deniz kabuğu ikamesi yapılarak numuneler üretilmiştir. Şekil 3 'te deniz kabuğu ikamesi yapılan betonlar görülmektedir. Kür havuzunda 28 gün kür edilen $15 \times 15 \times 15 \mathrm{~cm}$ boyutlu beton küp numuneler basınç testine tabi tutularak basınç dayanımları hesaplanmıştır.
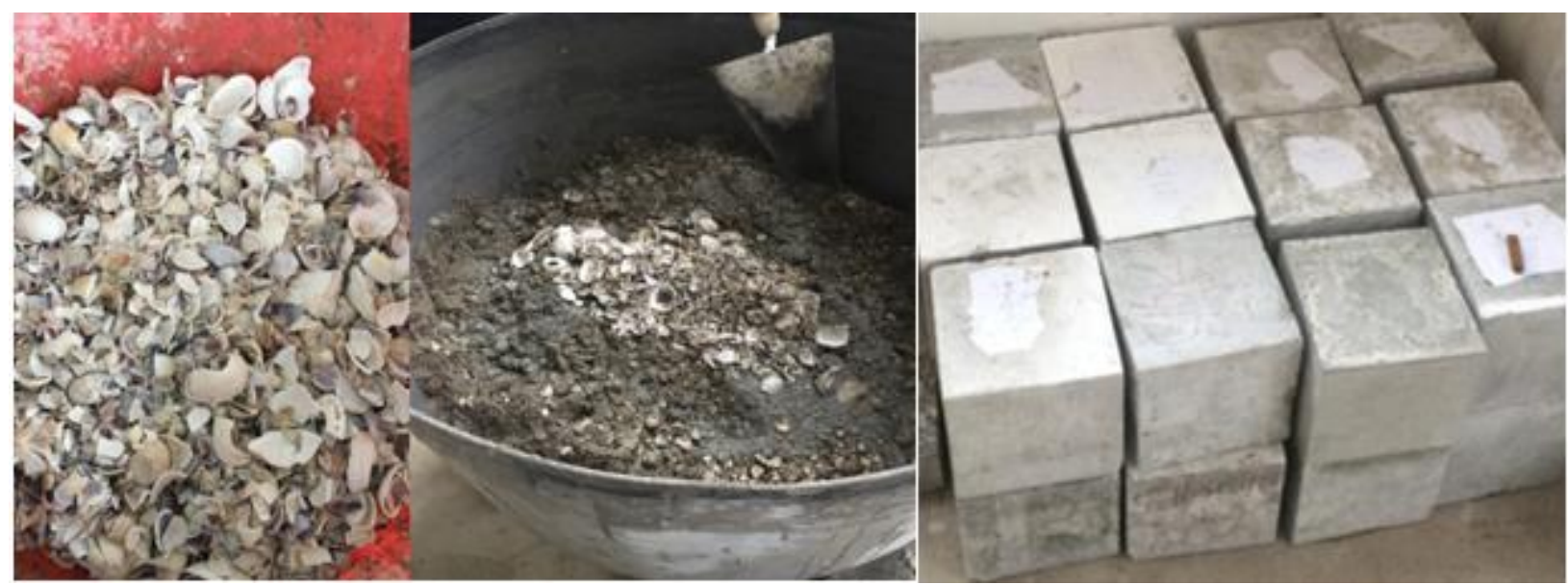

Şekil 3. Deniz kabuklu betonların hazırlanması

\section{Deney Sonuçları}

Yapılan deneysel çalışmalar sonucunda elde edilen verilerden normal dayanımlı ve düşük dayanımlı beton numunelerin deniz kumu ve deniz kabuğu ikameli karışımlarının 28 günlük ortalama basınç dayanımları hesaplanarak Tablo 4'te verilmiştir. Her beton türünde üç adet numune ile yapılan testler sonucunda ortalama basınç dayanımları normal dayanımlı betonlarda referans betonun dayanımı yaklaşı $29 \mathrm{MPa}$ ve düşük dayanımlı betonlarda yaklaşık $16 \mathrm{MPa}$ olmak üzere grafik halinde karşılaştırılarak Şekil 4 ve Şekil 5'de verilmiştir. 
Tablo 4. Basınç dayanım ortalamaları

\begin{tabular}{lcc}
\hline & $\begin{array}{c}\text { Normal Dayanımlı } \\
\text { (MPa) }\end{array}$ & $\begin{array}{c}\text { Düşük Dayanımlı } \\
\text { (MPa) }\end{array}$ \\
\hline Referans Betonlar & 28,8 & 16,1 \\
\hline Deniz Kumlu & 27,4 & 14,5 \\
\hline Deniz Kabuklu \%3 & 24,6 & 9,6 \\
\hline Deniz kabuklu \%6 & 21,4 & 8,8 \\
\hline
\end{tabular}

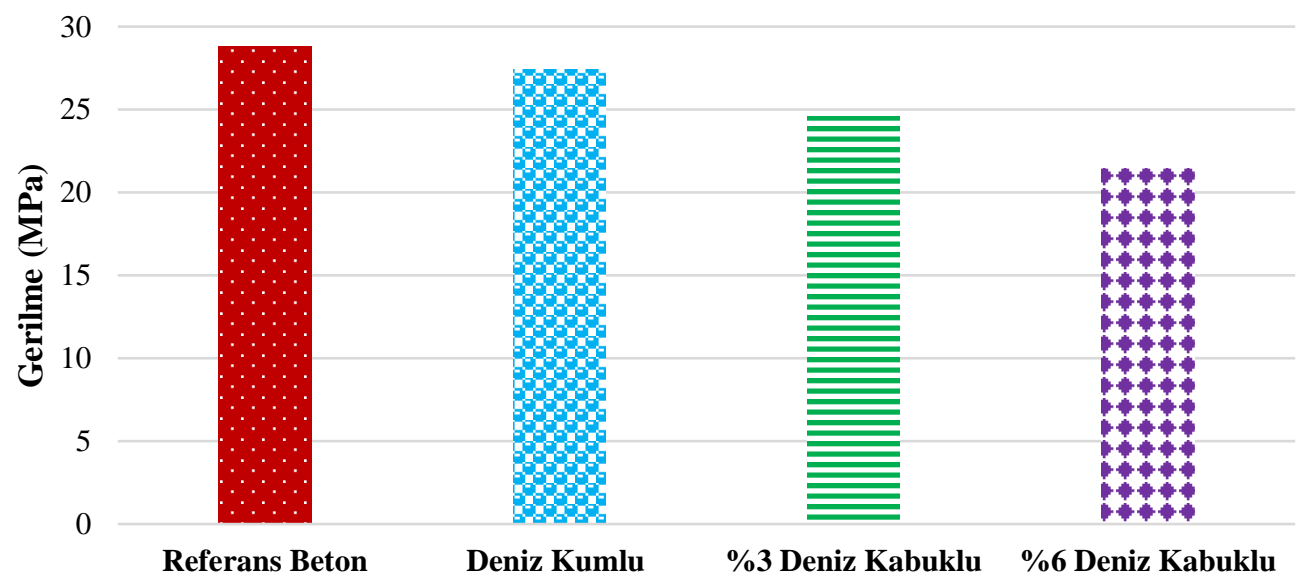

Şekil 4. Normal dayanımlı betonların ortalama basınç dayanımları

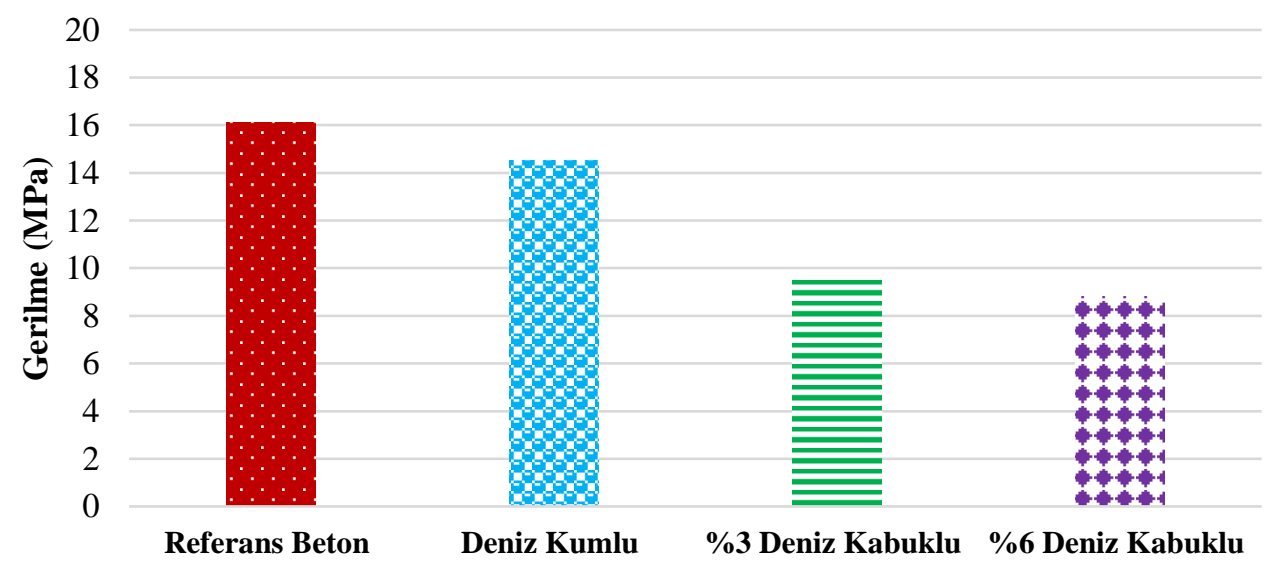

Şekil 5. Düşük dayanımlı betonların ortalama basınç dayanımları

Betonların basınç dayanımları incelendiğinde normal dayanımlı betonlar $29 \mathrm{MPa}$ ve düşük dayanımlı betonlar $16 \mathrm{MPa}$ basınç dayanımına sahip oldukları görülmektedir. Normal dayanımlı betonlarda referans betonlara göre deniz kumlu betonların yaklaşı $\% 4,9$ oranında dayanım kaybına uğradığ1, \%3 deniz kabuklu betonlarda \%14,6 ve \%6 deniz kabuklu betonlarda \%25,7 oranında basınç dayanımının azaldığı belirlenmiştir. Düşük dayanımlı betonlarda referans 
betonlara göre deniz kumlu, \%3 deniz kabuklu ve \%6 deniz kabuklu betonlarda tespit edilen basınç dayanım kayıplarının sırasıyla \%9,9, \%40 ve \%45 oranında olduğu tespit edilmiştir. Bu durum ülkemizdeki mevcut yapıların betonlarında deniz kabuklu ve deniz kumu kullanılanların büyük bir risk altında olduğunu göstermektedir. Referans betonlara göre deniz kumlu betonlarda belirlenen kısmi dayanım kayıplarının deniz kumunun maksimum tane çapının düşük ve granülometri dağılımın iyi olmadığından kaynaklı olarak yorumlanabilir.

Ülkemizde hazır beton kullanımın olmadığı yıllarda karşım reçetesi hazırlanmadan üretilen betonlar düşünülerek tasarlanan düşük dayanımlı betonların daha yüksek dayanımlı betonlara göre daha büyük oranlarda dayanım kayıplarına mazur kalacağı görülmüştür. Özelikle deniz kabuğu oranlarının her iki beton türünde aynı oranında olmasına rağmen normal dayanımlı betonlarda \%3 ve \%6 deniz kabuklu betonlar için dayanım kayıpları sırasıyla \%15-\%26 oranında iken düşük dayanımlı betonlarda bu oranlar sırasıyla \%40-\%45 olarak gerçekleşmiştir. Şekil 6'da basınç testleri sonucunda düşük yüklerde kırılan beton numunesinin çimento matrisi ve agrega yüzeylerinde kolaylıkla ayrıldı̆̆ı görülmektedir.

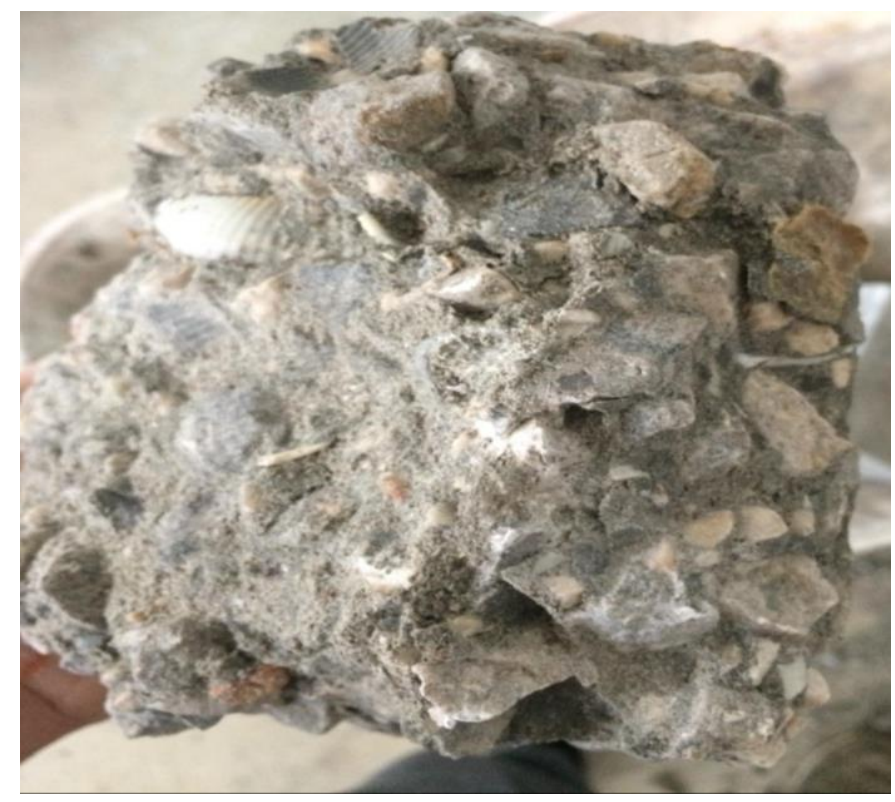

Şekil 6. Basınç testi sonrasında düşük dayanımlı beton numunesi

\section{Sonuç ve Öneriler}

Deneysel çalışmalar sonucunda normal ve düşük dayanımlı olmak üzere iki dayanım sınıfında üretilen deniz kumlu ve deniz kabuklu beton numunelerinin benzer karışım oranlarına sahip referans beton numunelerine göre basınç dayanımında oluşan farklılıklar tespit edilerek aşağıda özetlenmiştir:

- Normal dayanımlı betonlarda deniz kumuyla hazırlanan betonların basınç dayanımı referans betonlara göre yaklaşık \%5 oranında daha düşük dayanıma sahip olduğu tespit edilmiştir. 
- Normal dayanımlı \%3 deniz kabuğuyla hazırlanan beton numunelerinin referans betonlara göre ortalama basınç dayanımı $\% 15$ oranında azalmıştır.

- Normal dayanımlı \%6 deniz kabuklu beton numunelerinin dayanımı referans betonlara göre yaklaşık \%26 oranında azalmıştır.

- Düşük dayanımlı deniz kumuyla hazırlanan betonların basınç dayanımı referans betonlara göre yaklaşık \%10 oranında azalmıştır.

- Düşük dayanımlı \%3 deniz kabuklu beton numunelerinin referans betonlara göre ortalama basınç dayanımı yaklaşık \%40 oranında azalmıştır.

- Düşük dayanımlı \%6 deniz kabuğuyla hazırlanan beton numunelerinin ortalama basınç dayanımı referans betonlara göre yaklaşık \%45 oranında azalmıştır.

- Deniz kabuklarının beton basınç dayanımını düşük dayanımlı betonlarda daha yüksek oranda düşürdüğü belirlenmiştir. Normal dayanımlı betonlarda dayanım azalma oranları $\% 15$ - \%26 oranında iken düşük dayanımlı betonlarda \%40-\%45'e kadar çıkmaktadır.

- Deniz kıyısına yakın bölgelerde çok sayıdaki yapının deniz kumlu ve kabuklu malzemeler kullanılarak yapıldığı düşünülmesinden dolayı acil olarak bu yapıların kentsel dönüşüme dahil edilmesi yada güçlendirilme yapılmasının gerekliliği bir kez daha ortaya çıkmıştır.

\section{Kaynaklar}

[1] Sarıbıyık M., Sümer M., Fırat S. and Aydın F. Investigation of Concrete Quality of Collapsed-Heavily Damaged Structures During The Marmara Earthquake. 8th International Conference on Inspection, Appraisal, Repairs \& Maintenance of Buildings and Structures. 18 - 20 December 2003. Singapore.

[2] https://tr.sputniknews.com/turkiye/201902111037593967-kartal-coken-bna-enkaz-denizkabugu/ (01.10.2019).

[3] P. Lertwattanaruk, N. Makul, C. Siripattarapravat, Utilization of ground waste seashells in cement mortars for masonry and plastering, J. Environ. Manage. 2012: 111 133-141.

[4] B. Zhong, Q. Zhou, C. Chan, Y. Yu, Structure and property characterization of oyster shell cementing material, Chin. J. Struct. Chem. 2012: 31 (1) 85-92.

[5] H. Ez-zaki, A. Diouri, S. Kamali-Bernard, O. Sassi, Composite cement mortars based on marine sediments and oyster shell powder, Mater. Constr. 2016: 66 (321) https://doi.org/10.3989/mc.2016.01915.

[6] N.H. Othman, B.H.A. Bakar, M.M. Don, M.A.M. Johari, Cockle shell ash replacement for cement and filler in concrete, Mal. J. Civ. Eng. 2013: 25 (2) 201-211.

[7] W. Kuo, H. Wang, C. Shu, D. Su, Engineering properties of controlled lowstrength materials containing waste oyster shells, Constr. Build. Mater. 2013: 46 128-133.

[8] K. Muthusamy, S.M.A. Nasir, A.M. Budiea, N. Nordin, Properties of cement sand brick containing finely crushed cockle shell as partial fine aggregates replacement, Concr. Res. Lett. 2016: 7 (4) 132-137.

[9] B. Safi, M. Saidi, A. Daoui, A. Bellal, A. Mechekak, K. Toumi, The use of seashells as a fine aggregate (by sand substitution) in self-compacting mortar (SCM), Constr. Build. Mater. 2015: 78 430-438.

[10] H. Cuadrado-Rica, N. Sebaibi, M. Boutouil, B. Boudart, Properties of ordinary concretes incorporating crushed queen scallop shells, Mater. Struct. 2016: 49 (5) 1805-1816. 
[11] S. Eo, S. Yi, Effect of oyster shell as an aggregate replacement on the characteristics of concrete, Mag. Concr. Res. 2015: 67 (15) 833-842.

[12] C. Martinez-Garcia, B. Gonzalez-Fonteboa, F. Martinez-Abella, D. Carro-Lopez, Performance of mussel shell as aggregate in plain concrete, Constr. Build. Mater. 2017: 139 $570-583$.

[13] A.E. Richardson, T. Fuller, Sea shells used as partial aggregate replacement in concrete, Str. Surv. 2013: 31 (5) 347-354.

[14] A.P. Adewuyi, T. Adegoke, Exploratory study of periwinkle shells as coarse aggregates in concrete works, ARPN J. Eng. Appl. Sci. 2008: 3 (6) 1-5.

[15] F. Falade, An investigation of periwinkle shells as coarse aggregate in concrete, Build. Environ. 1995: 30 (4) 573-577.

[16] C. Varhen, S. Carrillo, G. Ruiz, Experimental investigation of Peruvian scallop used as fine aggregate in concrete, Constr. Build. Mater. 2017: 136 533-540.

[17] TS 802, Türk Standartları Enstitüsü. Beton Karışım Tasarımı Hesap Esasları, 24.03.2016. 